\title{
Changes of Non-Sense Syllabic Word Scores and Preferences as a Function of Release Time on Multi-Channel Hearing Aids
}

\author{
Jihaeng Jeong, Kyoungwon Lee \\ Department of Audiology and Speech-Language Pathology, Hallym University of Graduate Studies, Seoul, Korea
}

다채널 보청기의 해제시간에 따른 무의미음절인지도와 선호도의 변화

정 지 행·이 경 원

한림국제대학원대학교 청각언어치료학과

\begin{abstract}
Purpose: To determine the effective release time (RT) for listening to Korean sounds when wearing hearing aids, we evaluated Korean non-sense syllabic word recognition scores (NSRS) and the clarity of conversation sounds, the size of noise, and the overall preferences as a function of RT. Methods: Twenty adults and elderly people with mild to severe sensorineural hearing loss were participated as subjects. In the quiet and noise environment, NSRS and preferences were evaluated after setting the RT of the multi-channel hearing aids to 70, 200, and 600 ms. Presentation level of non-sense syllabic word was $45 \mathrm{~dB} \mathrm{HL}$ and signal-to-noise ratio was $6 \mathrm{~dB}$ in noise environment. Results: NSRS was not different as a function of RT in quiet, but NSRS of $200 \mathrm{~ms}$ was higher than $70 \mathrm{~ms}$ and $600 \mathrm{~ms}$ in noise environment. However, clarity, loudness of noise, and overall preference did not show a difference in RT in a quiet and noisy environment. Conclusion: Through this study, it was confirmed that Korean NSRS can be affected by RT. Therefore, in order to develop a hearing aid fitting formula that is effective in recognition of Korean speech sound, it is necessary to consider the RT.
\end{abstract}

Key Words: Hearing aids, Release time, Compression threshold, Compression ratio, Hearing aid fitting formula.

Received: September 13, 2018 / Revised: October 1, 2018 / Accepted: October 4, 2018

Correspondence: Kyoungwon Lee, Department of Audiology and Speech-Language Pathology, Hallym University of Graduate Studies, 427 Yeoksam-ro, Gangnam-gu, Seoul 06197, Korea

Tel: +82-2-2051-4951 / Fax: +82-2-3453-6618 / E-mail: leekw@hallym.ac.kr

\section{INTRODUCTION}

비선형 보청기는 잘 알려진 것처럼 감각신경성 난청의 청력역 치레벨 및 역동범위를 개선하여 어음의 청취능력 및 명료도를 높이는 데 효과적이다. 또한 비선형 보청기는 압축역치(compression threshold, CT)와 압축비율(compression ratio, CR) 그 리고 압축시간(attack time, AT)과 해제시간(release time, RT) 을 적절하게 조절하여 신호대잡음비(signal-to-noise ratio, $\mathrm{SNR}$ ) 또는 자모음비(consonant-to-vowel ratio, CVR)를 개선 할 수 있어서 어음의 질적인 측면 또한 개선할 수 있다(Souza,

(c) This is an Open Access article distributed under the terms of the Creative Commons Attribution Non-Commercial License (https://creativecommons.org/licenses/by-nc/4.0) which permits unrestricted non-commercial use, distribution, and reproduction in any medium, provided the original work is properly cited.
2002). 그리고 다채널 보청기는 한 개의 증폭기에서 각 주파수 대역별 압축이 독립적으로 작동하는 시스템으로 음질을 포함 하여 청력역치레벨, 역동범위, SNR 및 CVR을 더욱 효과적으 로 개선할 수 있다(Hansen, 2002).

우선 비선형 보청기의 매개변수인 $\mathrm{CT}, \mathrm{CR}, \mathrm{AT}$ 및 RT의 조 절에 따른 증폭음의 효과를 살펴보면 다음과 같다. 첫째, 난청 인이 사용하는 보청기의 보통 대화음에 대한 이득이 같을 때 CT는 낮게 설정할수록 더 높은 이득이 발생한다. 따라서 청력 역치레벨을 포함하여 좁은 역동범위를 개선하거나 에너지가 작 은 어음을 효과적으로 청취하기 위해서는 $\mathrm{CT}$ 를 낮게 설정한 다. 그러나 너무 낮게 설정한 CT는 주변의 작은 잡음 또한 증 폭하여 어음의 인지를 방해할 수 있으며, 음질 또한 저하된다 고 보고하였다(Barker et al., 2001; Choi \& Lee, 2011; Lee, 
2008). Barker \& Dillon(1999), Barker et al.(2001) 등은 중도에 서 고심도의 감각신경성 난청인은 $50 \mathrm{~dB} \mathrm{SPL}$ 이하보다 대화음 레벨 부근인 $65 \mathrm{~dB}$ SPL 전후의 CT를 선호한다고 보고하였다. 국내의 연구에서도 순음 청력역치레벨의 평균이 $42.5 ~ 75.0 \mathrm{~dB}$ $\mathrm{HL}$ 인 감각신경성 난청인은 $65 \mathrm{~dB}$ SPL 전후의 CT를 선호한다 고 보고하였다(Lee et al., 2008a). 둘째, CR은 감각신경성 난청 인의 역동범위와 관계가 있으며, 청력역치레벨이 높을수록 역 동범위가 좁아지기 때문에 $\mathrm{CR}$ 은 높아진다. 그러나 Boike \& Souza(2000)의 보고에서는 경도에서 중도의 감각신경성 난청인 은 조용한 환경에서 $\mathrm{CR}$ 에 따른 어음인지도는 변화가 없었으며, 잡음 환경에서는 $\mathrm{CR}$ 이 높을수록 음질이 나빠졌다고 하였다. 셋 째, AT는 높은 음압이 제공되었을 때 큰 소리로부터 청각기관 을 보호하기 위하여 대부분 빠른 AT를 사용한다. 넷째, RT는 빠를 때 CVR이 개선되지만 SNR은 나빠진다(Gatehouse et al., 2006; Hansen, 2002; Neuman et al., 1998). 그리고 RT가 느리 면 빠를 때와는 반대로 SNR이 개선되지만 CVR은 나빠져서 RT에 따른 어음인지도와 선호도가 다양하게 나타난다(Gatehouse et al., 2006; Hansen, 2002; Jenstad \& Souza, 2005). RT에 따른 음질의 선호도와 어음인지도에 대한 연구를 살펴보 면 Hansen(2002)과 Neuman et al.(1995) 등의 보고에서 건청 인 및 난청인은 $20 \mathrm{~dB}$ SPL의 CT를 가진 보청기에서 $400 \mathrm{~ms}$ 이하에 비해서 1 초에서 4 초의 긴 RT가 주변 소음을 제어하여 선호도 및 쾌적도가 증가한다고 하였다. 그리고 한국어음을 이 용한 RT의 연구에서 Han et al.(2017)은 RT를 $50 \mathrm{~ms}$ 와 $500 \mathrm{~ms}$ 로 설정한 후 50\% 문장인지 SNR, 날카로움(sharpness), 선명도 (clarity), 주변 잡음(background noise) 등에서 차이가 없었음 을 보고하였다.

청각 손실의 종류, 청력역치레벨의 정도에 따른 다채널 보청 기의 이득과 출력음압레벨 90(output sound pressure level 90 $\mathrm{dB}$ input) 그리고 $\mathrm{CT}, \mathrm{CR}, \mathrm{AT}$ 및 $\mathrm{RT}$ 를 효과적으로 결정하기 위해서 보청기적합공식(hearing aid fitting formula)을 사용한 다. 그렇지만 현재 한국 내에서 사용하고 있는 보청기적합공식 은 Lee \& $\operatorname{Kim}(2011)$ 이 지적하였듯이 영어 또는 이와 비슷한 스펙트럼을 가진 언어에 최적화되어 있다. 하지만 2000년대 중 반 이후 어음의 특성에 있어서 영어와 한국어의 차이를 나타내 는 연구가 다수 있었다. 장기평균어음스펙트럼(long-term average speech spectrum)을 살펴본 Lee et al.(2008b)의 연구에 서는 한국어음의 저주파수와 고주파수의 에너지 차이는 한국 어가 영어에 비해서 더 크게 나타났다고 보고하였다. 그리고 Jin et al.(2015)과 Lee \& Kim(2012)의 연구에서 대역중요함수 (band importance function)는 영어의 경우 $2,000 \mathrm{~Hz}$ 부근에 서 높게 나타나지만 한국어의 경우는 단음절어와 문장 모두 $1,000 \mathrm{~Hz}$ 이하의 저주파수 대역에서 높게 나타났다고 보고하
였다. 이러한 장기평균어음스펙트럼, 대역중요기능은 보청기적 합공식의 산출에 영향을 주며(Byrne et al., 2001), 이는 Lee \& $\mathrm{Kim}(2012)$ 도 언급하였듯이 한국어음의 인지 및 음질에 효과적 인 보청기적합공식의 개발이 필요함을 시사하고 있다.

Hansen(2002)과 Souza(2002)의 연구에서 언급하였듯이 RT 는 어음의 청취능력과 명료도, 음질, 잡음의 크기 등에 영향을 줄 수 있다. 이에 본 연구에서는 비선형 보청기의 보청기적합공 식의 개발에 도움을 주기 위해 조용한 곳 및 잡음하에서 RT에 따른 한국어 무의미 무성자음의 인지도, 문장의 선명도, 잡음의 크기 및 선호도, 그리고 무의미음절의 오류 패턴을 알아보았다.

\section{MATERIALS AND METHODS}

\section{연구 대상}

대상자는 20세 이상의 성인 및 노인으로 육안 관찰 시 외이 및 고막에 이상 소견이 없으며, 순음역치 $500,1,000,2,000 \mathrm{~Hz}$ 의 평균이 40 80 dB HL, 기골도 차가 $15 \mathrm{~dB}$ 이내인 감각신경 성 난청인으로 하였다. 대상자 수는 20명(남성 15 명, 여성 5명) 으로 평균 연령은 67.1세(범위; 25 83세, 표준편차; 18.08)였다. 모든 대상자는 좌측과 우측의 순음역치평균의 차이가 $15 \mathrm{~dB}$ 이내로 비슷하며, 측정 귀의 순음역치평균은 3 분법으로 54.5 $\mathrm{dB} \mathrm{HL}$ (범위; 41.7 76.7 dB HL, 표준편차; 10.95), 단어인지도 의 평균은 70.30(범위; 40 100\%)이었다. 대상자 중 2명(S7, S9) 은 보청기를 착용하지 않았으며, 나머지 대상자의 평균 보청기 착용 기간은 2.93년(범위; 0.5 20년, 표준편차; 4.81)이었다. 대 상자의 성별, 나이, 착용 귀, 보청기 착용 기간, 옥타브 주파수별 청력역치레벨, 단어인지도(\%)는 Table 1에 나타내었다.

\section{실험 장비}

기도 및 골도 청력역치레벨 및 단어인지도검사는 Harp-Basic (Starkey Hearing Technologies, Eden Prairie, MN, USA)과 $\mathrm{TDH}-39$ 헤드폰을 사용하였으며, 검사음은 웨이브파일 형식으 로 변환한 파일의 저장은 노트북(Model: Lenova G50-45, Beijing, China), 어음의 제시는 노트북과 청력 검사기를 연결한 후 방음실 내의 8 옴 $(\mathrm{Ohm})$ 스피커를 통해 제시하였다. 검사음의 제작은 Adobe Audition (version 3.0, San Jose, CA, USA), 실 험에 사용한 보청기는 Beltone 사(Ballerup, Denmark)의 17 채 널 귀걸이형의 보청기(Model; TRUST 17)를 사용하였다. 보청 기의 특성 측정은 Fonix 8000 (Frye Electronics, Inc., Beaverton, OR, USA)을 이용하여 AT와 RT는 ANSI S3.22 (2003), 압축비율은 ANSI S3.42 (1992)를 이용하여 측정하였다. 
Table 1. General and hearing information for the study subjects

\begin{tabular}{|c|c|c|c|c|c|c|c|c|c|c|c|}
\hline \multirow{2}{*}{ Subjects } & \multirow{2}{*}{ Sex } & \multirow{2}{*}{ Age (year) } & \multirow{2}{*}{ Ear } & \multirow{2}{*}{$\begin{array}{c}\text { HA experience } \\
\text { (year) }\end{array}$} & \multicolumn{5}{|c|}{ Levels of pure-tone thresholds in $\mathrm{Hz}$} & \multirow{2}{*}{$\begin{array}{c}\text { PTA } \\
(\mathrm{dB} \mathrm{HL})\end{array}$} & \multirow{2}{*}{$\begin{array}{l}\text { WRS } \\
(\%)\end{array}$} \\
\hline & & & & & 250 & 500 & 1,000 & 2,000 & 4,000 & & \\
\hline S1 & $\mathrm{M}$ & 69 & $\mathrm{R}$ & 2.5 & 40 & 45 & 70 & 85 & 95 & 66.7 & 44 \\
\hline S2 & $\mathrm{M}$ & 79 & $\mathrm{~L}$ & 2.5 & 70 & 75 & 70 & 85 & 85 & 76.7 & 40 \\
\hline S3 & $\mathrm{M}$ & 77 & $\mathrm{R}$ & 1.5 & 30 & 30 & 50 & 50 & 65 & 43.3 & 90 \\
\hline S4 & M & 76 & $\mathrm{R}$ & 0.5 & 35 & 40 & 50 & 65 & 70 & 51.7 & 56 \\
\hline S5 & $\mathrm{M}$ & 75 & $\mathrm{R}$ & 1.0 & 50 & 40 & 40 & 45 & 50 & 41.7 & 88 \\
\hline S6 & $\mathrm{M}$ & 68 & $\mathrm{~L}$ & 0.5 & 30 & 35 & 50 & 60 & 80 & 48.3 & 84 \\
\hline S7 & $\mathrm{F}$ & 74 & $\mathrm{R}$ & 0.0 & 55 & 55 & 55 & 55 & 70 & 55.0 & 72 \\
\hline S8 & $\mathrm{F}$ & 73 & $\mathrm{R}$ & 2.0 & 45 & 40 & 45 & 40 & 55 & 41.7 & 100 \\
\hline S9 & $\mathrm{F}$ & 76 & $\mathrm{R}$ & 0.0 & 55 & 55 & 40 & 50 & 60 & 48.3 & 72 \\
\hline S10 & M & 83 & $\mathrm{~L}$ & 3.5 & 50 & 50 & 55 & 60 & 75 & 55.0 & 72 \\
\hline S11 & M & 73 & $\mathrm{R}$ & 1.5 & 40 & 45 & 50 & 55 & 65 & 50.0 & 76 \\
\hline S12 & M & 70 & $\mathrm{~L}$ & 3.0 & 60 & 50 & 55 & 65 & 80 & 56.7 & 60 \\
\hline S13 & M & 63 & $\mathrm{R}$ & 0.3 & 45 & 40 & 45 & 45 & 70 & 43.3 & 92 \\
\hline S14 & $\mathrm{M}$ & 78 & $\mathrm{~L}$ & 1.5 & 60 & 60 & 65 & 55 & 75 & 60.0 & 52 \\
\hline S15 & $\mathrm{F}$ & 82 & $\mathrm{R}$ & 0.5 & 60 & 55 & 50 & 50 & 55 & 51.7 & 44 \\
\hline S16 & F & 82 & $\mathrm{~L}$ & 0.5 & 55 & 60 & 60 & 55 & 60 & 58.3 & 64 \\
\hline S17 & $\mathrm{M}$ & 62 & $\mathrm{R}$ & 20.0 & 40 & 75 & 75 & 75 & 75 & 75.0 & 72 \\
\hline S18 & M & 26 & $\mathrm{R}$ & 0.5 & 45 & 40 & 45 & 55 & 55 & 46.7 & 84 \\
\hline S19 & $\mathrm{M}$ & 25 & $\mathrm{~L}$ & 1.0 & 15 & 35 & 50 & 55 & 50 & 46.7 & 100 \\
\hline S20 & M & 31 & $\mathrm{R}$ & 10.0 & 80 & 70 & 80 & 70 & 100 & 73.3 & 44 \\
\hline Mean & - & 67.10 & - & 2.93 & 48.00 & 49.75 & 55.00 & 58.75 & 69.50 & 54.50 & 70.30 \\
\hline SD & - & 18.08 & - & 4.81 & 14.90 & 13.23 & 11.47 & 12.34 & 14.04 & 10.95 & 19.24 \\
\hline
\end{tabular}

HA: hearing aid, WRS: word recognition score, PTA: pure tone threshold average, SD: standard deviation

\section{음원 제작}

비선형 보청기의 매개변수인 CT, CR, AT 및 RT는 어음 및 잡음의 에너지에 영향을 줄 수 있다. RT에 따른 어음 및 잡음의 에너지 변화를 살펴보면 RT가 빠른 경우는 모음 뒤에 나타나 는 무성자음과 잡음 에너지의 크기를 원래대로 환원하여 CVR 을 개선할 수 있지만 SNR을 나쁘게 할 수 있다. 그러나 RT가 느린 경우는 모음 뒤에 나타나는 무성자음과 잡음 에너지의 크 기를 압축한 상태로 유지하여 CVR은 나빠지며, SNR은 개선된 다(Souza, 2002). 이에 본 실험에 사용한 어음은 RT에 따라 모 음 뒤에 나타나는 무성자음 및 잡음의 에너지에 변화를 주기 위해 No \& Lee(2012)의 연구에서 사용한 한국어 무성자음 '사 $\left(\mathrm{s}^{\mathrm{h}} \mathrm{a}\right)$,' '차( $\left(\mathrm{tc}^{\mathrm{h}} \mathrm{a}\right)$,' '카 $\left(\mathrm{k}^{\mathrm{h}} \mathrm{a}\right)$,' '타( $\left.\mathrm{t}^{\mathrm{h}} \mathrm{a}\right)$ ', '파 $\left(\mathrm{p}^{\mathrm{h}} \mathrm{a}\right)$ '를 Table 2 와 같이 2 음절로 연결하여 사용하였다. 이때 음절 간의 간격은 보청기에 서 구현할 수 있는 중간 정도의 RT인 $200 \mathrm{~ms}$ 로 설정하였다.

\section{실험 절차}

\section{보청기의 조절}

보청기의 조절은 첫째, 보청기는 보청기적합공식 National Acoustic Laboratories' nonlinear fitting procedure, version 1 (NAL-NL1)에서 제시하는 이득 및 출력음압레벨 90으로 조절 하였다. 둘째, 대상자가 보통 크기의 소리를 편안하게 들을 수 있도록 음량 조절기를 이용하여 보청기의 이득을 조절하였다.
Table 2. Non-sense syllabic words used in the experiment

\begin{tabular}{|c|c|c|c|c|}
\hline$s^{h} a-s^{h} a$ & $\mathrm{tc}^{\mathrm{h}} \mathrm{a}-\mathrm{s}^{\mathrm{h}} \mathrm{a}$ & $\mathrm{k}^{\mathrm{h}} \mathrm{a}-\mathrm{s}^{\mathrm{h}} \mathrm{a}$ & $\mathrm{t}^{\mathrm{h}} \mathrm{a}-\mathrm{s}^{\mathrm{h}} \mathrm{a}$ & $\mathrm{p}^{\mathrm{h}} \mathrm{a}-\mathrm{s}^{\mathrm{h}} \mathrm{a}$ \\
\hline$s^{\mathrm{h}} \mathrm{a}-\mathrm{tc}^{\mathrm{h}} \mathrm{a}$ & $\mathrm{tc}^{\mathrm{h}} \mathrm{a}-\mathrm{t} 6^{\mathrm{h}} \mathrm{a}$ & $\mathrm{k}^{\mathrm{h}} \mathrm{a}-\mathrm{t} 6^{\mathrm{h}} \mathrm{a}$ & $\mathrm{t}^{\mathrm{h}} \mathrm{a}-\mathrm{t} 6^{\mathrm{h}} \mathrm{a}$ & $\mathrm{p}^{\mathrm{h}} \mathrm{a}-\mathrm{t} 6^{\mathrm{h}} \mathrm{a}$ \\
\hline$s^{h} a-k^{h} a$ & $\mathrm{tc}^{\mathrm{h}} \mathrm{a}-\mathrm{k}^{\mathrm{h}} \mathrm{a}$ & $\mathrm{k}^{\mathrm{h}} \mathrm{a}-\mathrm{k}^{\mathrm{h}} \mathrm{a}$ & $\mathrm{t}^{\mathrm{h}} \mathrm{a}-\mathrm{k}^{\mathrm{h}} \mathrm{a}$ & $\mathrm{p}^{\mathrm{h}} \mathrm{a}-\mathrm{k}^{\mathrm{h}} \mathrm{a}$ \\
\hline$s^{\mathrm{h}} \mathrm{a}-\mathrm{t}^{\mathrm{h}} \mathrm{a}$ & $\mathrm{t}^{\mathrm{h}} \mathrm{a}-\mathrm{t}^{\mathrm{h}} \mathrm{a}$ & $\mathrm{k}^{\mathrm{h}} \mathrm{a}-\mathrm{t}^{\mathrm{h}} \mathrm{a}$ & $t^{\mathrm{h}} \mathrm{a}-\mathrm{t}^{\mathrm{h}} \mathrm{a}$ & $\mathrm{p}^{\mathrm{h}} \mathrm{a}-\mathrm{t}^{\mathrm{h}} \mathrm{a}$ \\
\hline$s^{h} a-p^{h} a$ & $\mathrm{t}^{\mathrm{h}} \mathrm{a}-\mathrm{p}^{\mathrm{h}} \mathrm{a}$ & $\mathrm{k}^{\mathrm{h}} \mathrm{a}-\mathrm{p}^{\mathrm{h}} \mathrm{a}$ & $\mathrm{t}^{\mathrm{h}} \mathrm{a}-\mathrm{p}^{\mathrm{h}} \mathrm{a}$ & $\mathrm{p}^{\mathrm{h}} \mathrm{a}-\mathrm{p}^{\mathrm{h}} \mathrm{a}$ \\
\hline
\end{tabular}

셋째, 보청기의 RT는 $70 \mathrm{~ms}$ 전후의 빠른 해제시간(fast release time, FRT), $200 \mathrm{~ms}$ 전후의 중간 해제시간(medium release time, MRT), $600 \mathrm{~ms}$ 전후의 느린 해제시간(slow release time, SRT)으로 조절하였다. 모든 옥타브 주파수에서 청력역치레벨 이 $50 \mathrm{~dB}$ HL 그리고 $70 \mathrm{~dB}$ HL일 때 NAL-NL1에 의한 FRT, $\mathrm{MRT}$, SRT에 해당하는 AT와 RT는 Table 3와 같다. 그리고 착 용한 보청기의 옥타브 주파수별 압축비율은 Table 4에 대상자 별로 나타내었다.

\section{RT에 따른 무의미음절인지도의 측정}

무의미음절인지도 측정 전 보청기를 통하여 스피커에서 제시 되는 음원을 편안한 강도로 들을 수 있는지 예비 문장을 통하 여 확인한 후 FRT, MRT, SRT의 RT를 무작위로 변경하여 조 용한 환경과 잡음 환경에서 어음을 $50 \mathrm{~dB} \mathrm{HL}$ 로 제시하였다. 대상자가 바뀔 때마다 청취 환경을 바꾸어 제시하였다. 잡음의 강도는 $44 \mathrm{~dB} \mathrm{HL}(+6 \mathrm{~dB} \mathrm{SNR})$ 이었으며, 제시어음의 정답과 오답은 대상자가 따라 말하도록 한 후 두 번째 음절을 기준으 
로 평가하였다.

RT에 따른 선명도, 잡음의 크기 및 전체 선호도의 측정

선명도, 잡음의 크기 및 전체 선호도는 녹음한 문장 '가을이

Table 3. AT and RT at octave frequencies between $250-4,000 \mathrm{~Hz}$ by FRT, MRT, and SRT when entering $50 \mathrm{~dB} \mathrm{HL}$ and $70 \mathrm{~dB} \mathrm{HL}$ at all frequencies into NAL-NL1 fitting software

\begin{tabular}{|c|c|c|c|c|c|c|}
\hline \multirow{2}{*}{$\mathrm{Hz}$} & \multicolumn{2}{|c|}{ FRT } & \multicolumn{2}{|c|}{ MRT } & \multicolumn{2}{|c|}{ SRT } \\
\hline & $\mathrm{AT}$ & RT & AT & RT & $\mathrm{AT}$ & RT \\
\hline \multicolumn{7}{|l|}{$50 \mathrm{~dB} \mathrm{HL}$} \\
\hline 250 & 0 & 60 & 8 & 212 & 4 & 360 \\
\hline 500 & 12 & 63 & 12 & 260 & 18 & 643 \\
\hline 1,000 & 12 & 74 & 12 & 200 & 24 & 533 \\
\hline 2,000 & 9 & 71 & 8 & 175 & 20 & 604 \\
\hline 4,000 & 17 & 74 & 14 & 119 & 25 & 709 \\
\hline \multicolumn{7}{|l|}{$70 \mathrm{~dB}$ HL } \\
\hline 250 & 0 & 100 & 8 & 290 & 8 & 190 \\
\hline 500 & 8 & 79 & 9 & 268 & 12 & 405 \\
\hline 1,000 & 9 & 73 & 9 & 197 & 11 & 491 \\
\hline 2,000 & 8 & 79 & 8 & 195 & 13 & 617 \\
\hline 4,000 & 13 & 74 & 12 & 187 & 27 & 954 \\
\hline
\end{tabular}

AT: attack time, RT: release time, FRT: fast release time, MRT: medium release time, SRT: slow release time, NAL-NL1: National Acoustic Laboratories' nonlinear fitting procedure, version 1

Table 4. CR at each frequency of hearing aids used in present research

\begin{tabular}{ccccc}
\hline \multirow{2}{*}{ Subjects } & \multicolumn{3}{c}{ Compression ratio in frequency $(\mathrm{Hz})$} \\
\cline { 2 - 5 } & 500 & 1,000 & 2,000 & 4,000 \\
\hline S1 & $1.4: 1$ & $1.8: 1$ & $1.5: 1$ & $1.1: 1$ \\
S2 & $1.4: 1$ & $1.9: 1$ & $1.7: 1$ & $1.3: 1$ \\
S3 & $1.3: 1$ & $1.6: 1$ & $1.8: 1$ & $1.2: 1$ \\
S4 & $1.4: 1$ & $1.8: 1$ & $1.8: 1$ & $1.3: 1$ \\
S5 & $1.4: 1$ & $1.8: 1$ & $2.0: 1$ & $1.5: 1$ \\
S6 & $1.5: 1$ & $1.7: 1$ & $1.8: 1$ & $1.2: 1$ \\
S7 & $1.4: 1$ & $1.8: 1$ & $1.9: 1$ & $1.1: 1$ \\
S8 & $1.4: 1$ & $1.6: 1$ & $1.6: 1$ & $1.4: 1$ \\
S9 & $1.5: 1$ & $1.9: 1$ & $2.0: 1$ & $1.4: 1$ \\
S10 & $1.4: 1$ & $2.4: 1$ & $2.2: 1$ & $1.2: 1$ \\
S11 & $1.4: 1$ & $1.9: 1$ & $1.9: 1$ & $1.3: 1$ \\
S12 & $1.5: 1$ & $1.7: 1$ & $1.9: 1$ & $1.2: 1$ \\
S13 & $1.4: 1$ & $1.8: 1$ & $2.0: 1$ & $1.3: 1$ \\
S14 & $1.4: 1$ & $1.7: 1$ & $2.0: 1$ & $1.3: 1$ \\
S15 & $1.4: 1$ & $1.9: 1$ & $2.0: 1$ & $1.4: 1$ \\
S16 & $1.4: 1$ & $1.7: 1$ & $2.2: 1$ & $1.6: 1$ \\
S17 & $1.5: 1$ & $1.7: 1$ & $2.4: 1$ & $1.5: 1$ \\
S18 & $1.4: 1$ & $1.7: 1$ & $1.8: 1$ & $1.4: 1$ \\
S19 & $1.4: 1$ & $1.7: 1$ & $1.8: 1$ & $1.5: 1$ \\
S20 & $1.5: 1$ & $1.8: 1$ & $2.1: 1$ & $1.2: 1$ \\
Mean & $1.4: 1$ & $1.8: 1$ & $1.9: 1$ & $1.3: 1$ \\
\hline CR 5 : $: 1$ & &
\end{tabular}

CR: compression ratio
오면 나무에 단풍이 든다.를 조용한 환경 및 잡음 환경에서 들 려준 후 평가하였다. 측정 전 평가의 목적을 대상자에게 설명한 후 조용한 환경과 잡음 환경에서 들려주었으며, 들려줄 때마다 조용한 환경에서는 선명도와 전체 선호도, 잡음 환경에서는 선 명도, 잡음의 크기 및 전체적인 선호도를 평가하였다. 선호도 평가는 Figure 1 과 같이 $10 \mathrm{~cm}$ 의 직선 위에 직접 표시하게 한 후 눈금자를 이용하여 측정하였다.

\section{오류 패턴}

대상자들이 어음의 인지에 있어서 자주 범하는 오류의 형태 를 확인하기 위해 RT (FRT, MRT, SRT)에 따른 무의미음절의 오류 패턴을 살펴보았다.

\section{통계 분석}

조용한 환경 및 잡음 환경의 청취 조건과 RT의 조건에 따른 무의미음절인지도의 차이는 반복측정 이원분산분석(two-way ANOVA with repeated measure)을 이용하여 확인하였다. 각 각의 환경에서 RT에 따른 무의미음절인지도의 차이는 반복측 정 일원분산분석(one-way ANOVA with repeated measure), 사후 분석은 Bonferroni를 통하여 분석하였으며, RT에 따른 심리 음향적인 차이는 Friedman의 비모수검정(Friedman test) 으로 확인하였다. 본 연구의 통계 분석에서는 SPSS version 25 (IBM Corp., Armonk, NY, USA)를 사용하였다.

\section{RESULTS}

본 연구에서는 조용한 환경과 $+6 \mathrm{~dB} \mathrm{SNR}$ 의 잡음 환경에서 다채널 보청기의 RT를 FRT, MRT, SRT로 설정하여 RT의 변화 에 따른 무의미음절의 인지도와 음질의 선호도를 비교하였다.

\section{무의미음절인지도}

무의미음절인지도를 종속변수로 반복측정 이원분산분석을 시행한 결과(그룹 내 변수: RT, 환경) 환경에 따라서는 유의미 한 차이가 나타나지 않았으나 $[\mathrm{F}(1,19)=0.07, p>0.05], \mathrm{RT}$ 에

\begin{tabular}{|c|c|c|}
\hline \multirow{2}{*}{ Clarity } & 0 & 10 \\
\hline & Very unclear & Very clear \\
\hline \multirow{2}{*}{ Loudness of noise } & 0 & 10 \\
\hline & Very quiet & Very noisy \\
\hline \multirow{2}{*}{ Overall preference } & 0 & 10 \\
\hline & Very bad & Very good \\
\hline
\end{tabular}

Figure 1. Rating scales of sound clarity, loudness of noise, and overall preferences. 
따른 의미 있는 차이가 나타났다 $[\mathrm{F}(2,38)=4.41, p<0.05]$. Figure 2에서 FRT, MRT, SRT에 따른 무의미음절인지도는 조 용한 환경에서 각각 $35.70 \%$ (표준편차: 11.83), 30.80\%(표준편 차: 11.54), $31.40 \%$ (표준편차: 11.11)로 나타났으나 유의미한 차 이는 없었다[F(2,38) $=3.10, p>0.05]$. 그러나 잡음 환경에서는 $31.60 \%$ (표준편차: 10.37), 37.40\%(표준편차: 11.55), 30.00\%(표 준편차: 10.90)로 유의미한 차이가 나타났다 $[\mathrm{F}(2,38)=4.41, p<$ 0.05]. 사후 분석을 실시한 결과, $\mathrm{FRT}$ 와 $\mathrm{MRT}[\mathrm{F}(2,38)=9.63$, $p<0.05]$, MRT와 SRT $[\mathrm{F}(2,38)=9.63, p<0.05]$ 간에 유의 미한 차이가 나타났다.

$\mathrm{RT}$ 및 환경의 이원상호작용 $[\mathrm{F}(2,38)=6.66, p<0.05]$ 은 유의 하였다. 유의한 이원상호작용을 확인하기 위해 조용한 환경과 잡음 환경에서 사후 분석 비교를 시행하였다. 조용한 환경에서 $\mathrm{RT}$ 에 따른 차이가 유의하지 않았으나, 잡음 환경에서는 MRT 에서 측정한 결과가 FRT와 SRT의 RT를 적용한 결과보다 유 의하게 높게 나타났다 $(p<0.05)$.

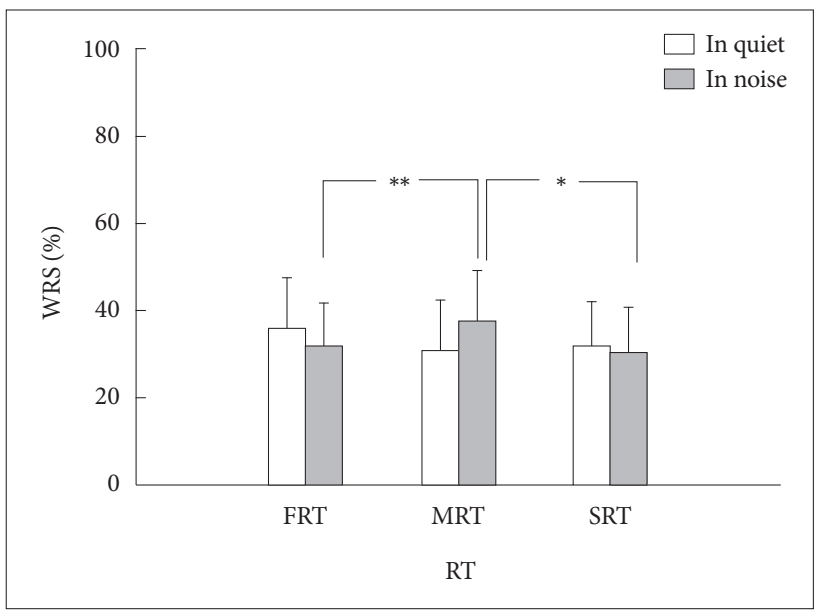

Figure 2. Non-sense syllabic WRS as a function of RT in quiet and noisy condition (error bar: standard deviation). [FRT (70 ms), MRT (200 ms), SRT (600 ms)]. ${ }^{*} p<0.01,{ }^{* *} p<0.001$. WRS: word recognition score, RT: release time, FRT: fast release time, MRT: medium release time, $\mathrm{SRT}$ : slow release time.

\section{선호 음질}

조용한 환경에서 FRT, MRT, SRT의 RT에 따라 난청인의 선 호도 설문 결과 선명도에서 각각의 평균점수가 6.59점(표준편 차: 2.06), 7.01점(표준편차: 2.06), 6.62점(표준편차: 2.27)이었으 며, 전체적인 선호도는 6.66점(표준편차: 1.99), 6.76점(표준편 차: 2.08), 6.57점(표준편차: 2.30)으로 나타났다(Figure 3). 그리 고 잡음 환경에서 FRT, MRT, SRT의 RT에 따라 난청인의 선 호도 설문 결과 선명도에서 각각의 평균점수가 6.29점(표준편 차: 1.64), 6.52점(표준편차: 2.36), 5.93점(표준편차: 2.18)이었으 며, 잡음의 크기에서 4.41점(표준편차: 2.44), 3.89점(표준편차: 2.24), 3.36점(표준편차: 2.31), 전체적인 선호도는 6.36점(표준편 차: 2.02), 7.08점(표준편차: 1.65), 6.69점(표준편차: 1.55)으로 나 타났다(Figure 3). Friedman 검정 결과 조용한 곳에서 선명도 $\left(\chi^{2}=3.80, p>0.05\right)$ 와 전체 선호도 $\left(\chi^{2}=1.09, p>0.05\right)$ 그리고 잡음 환경에서 선명도 $\left(\chi^{2}=0.53, p>0.05\right)$ 와 잡음의 크기 $\left(\chi^{2}=\right.$ $4.03, p<0.05)$, 전체 선호도 $\left(\chi^{2}=1.66, p>0.05\right)$ 는 모두 $\mathrm{RT}$ 에 따른 차이가 나타나지 않았다.

\section{오류 패턴}

RT (FRT, MRT, SRT)에 따른 무의미음절의 오류 패턴을 간 략히 살펴보면, 조용한 환경에서/사/는 /파/(36.08\%, 32.95\%, $41.30 \%)$ 와 /차/(31.96\%, 32.95\%, 39.13\%), /차/는 /파/(59.18\%, $50.00 \%, 75.61 \%), /$ 카/는 /파/(42.59\%, 37.04\%, 51.67\%)와 /차/ $(35.19 \%, 37.04 \%, 30.00 \%)$ 로 대치되었다. 그리고 /타/는 /파/ (39.06\%, 30.00\%, 49.18\%)와 /차/(26.69\%, 34.29\%, 31.15\%), /파/는 /차/(37.93\%, 24.59\%, 48.94\%)와 /카/(34.48\%, 32.79\%, $21.28 \%), /$ 타/(25.86\%, 39.34\%, 27.66\%)로 대치되는 경향이 있 었다. 또한 조음방법과 위치에 따라 분석한 결과 조용한 환경 에서 조음방법에 따라 대치율이 마찰음 $92.33 \%$, 파열음이 $58.78 \%$, 파찰음이 $43.33 \%$ 순으로 나타났으며, 위치에 따라 치조 음 $78.67 \%$, 연구개음 $56.00 \%$, 양순음 $55.33 \%$, 경구개음 $43.44 \%$ 로 나타났다.

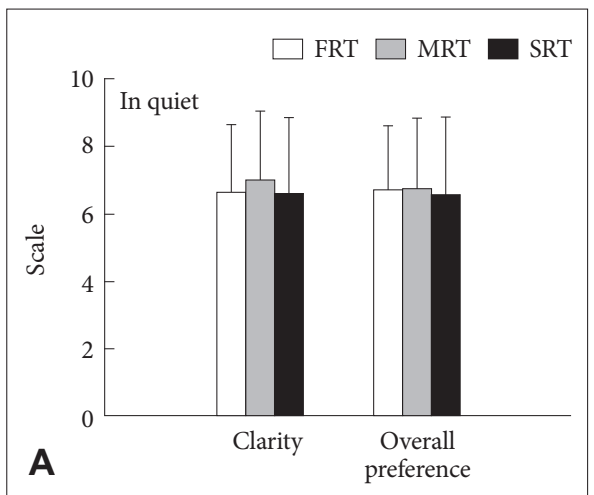

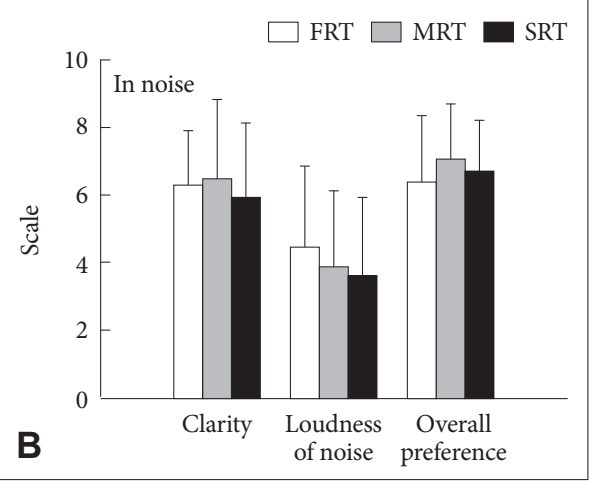

Figure 3. Subjective scaling results of clarity, loudness of noise, overall preference in quiet and noisy conditions [FRT (70 ms), MRT (200 ms), SRT (600 ms)]. FRT: fast release time, MRT: medium release time, SRT: slow release time. 
잡음 환경에서 /사/는 /파/(46.24\%, 35.29\%, 36.78\%)와 /차/ $(35.48 \%, 36.47 \%, 35.63 \%)$, /차/는 /파/(81.58\%, $60.00 \%$, $70.27 \%), /$ 카/는 /파/(44.29\%, 26.15\%, 40.63\%)와 /차/(31.43\%, $38.46 \%, 23.44 \%)$ 로 대치되었다. /타/는/파/(54.29\%, 42.62\%, $34.92 \%)$ 와 /차/(25.71\%, 31.15\%, 33.34\%), /파/는 /차/(43.48\%, $43.75 \%, 31.48 \%)$ 와 /타/(41.30\%, 35.42\%, 31.48\%)로 대치되는 경 향이 있었다. 또한 조음방법에 따라 대치율이 마찰음 $88.33 \%$, 파열음이 $60.11 \%$, 파찰음이 $38.33 \%$ 순으로 나타났으며, 위치에 따라 치조음 $76.50 \%$, 연구개음 $66.33 \%$, 양순음 $49.33 \%$, 경구개 음 $38.33 \%$ 로 나타났다(Table 5).

\section{DISCUSSIONS}

본 연구에서는 조용한 환경 및 잡음 환경에서 무성자음의 인 지도 그리고 녹음한 문장을 들려주었을 때 문장의 선명도, 잡 음의 크기, 전체적인 선호도 등이 RT에 따라서 차이가 나타나 는지를 확인하여 한국어음의 인지 또는 음질에 효과적인 보청 기적합공식의 개발에 도움을 주고자 하였다.

본 연구의 결과에서 선명도, 잡음의 크기, 전체적인 선호도는 조용한 곳 및 잡음 환경에서 RT에 따른 차이가 나타나지 않았 다. 그리고 조용한 곳에서의 RT에 따른 무의미음절인지도 또 한 차이가 나타나지 않았다. 그러나 잡음 환경에서의 무의미음 절인지도는 $200 \mathrm{~ms}$ 전후의 MRT에서 $70 \mathrm{~ms}$ 전후의 FRT와

Table 5. Phoneme substitutions as a function of release time (FRT, MRT, and SRT) in quiet and noisy environments

\begin{tabular}{|c|c|c|c|c|c|c|c|}
\hline \multirow{3}{*}{$\begin{array}{c}\text { Target } \\
\text { phoneme }\end{array}$} & \multirow{3}{*}{ Substitution } & \multicolumn{6}{|c|}{ Phoneme substitutions (\%) } \\
\hline & & \multicolumn{3}{|c|}{ In quiet } & \multicolumn{3}{|c|}{ In noise (6 dB SNR) } \\
\hline & & FRT & MRT & SRT & FRT & MRT & SRT \\
\hline \multirow[t]{6}{*}{$\mathrm{s}^{\mathrm{h}} \mathrm{a}$} & $t 6^{\mathrm{h}} \mathrm{a}$ & 31.96 & 32.95 & 39.13 & 35.48 & 36.47 & 35.63 \\
\hline & $\mathrm{k}^{\mathrm{h}} \mathrm{a}$ & 10.31 & 11.36 & 1.09 & - & 4.71 & 8.05 \\
\hline & $\mathrm{t}^{\mathrm{h}} \mathrm{a}$ & 18.56 & 19.32 & 17.39 & 17.20 & 20.00 & 16.09 \\
\hline & $\mathrm{p}^{\mathrm{h}} \mathrm{a}$ & 36.08 & 32.95 & 41.30 & 46.24 & 35.29 & 36.78 \\
\hline & tढ़a & 3.09 & 3.41 & 1.09 & - & 2.35 & 2.30 \\
\hline & ha & - & - & - & 1.07 & 1.18 & 1.15 \\
\hline \multirow[t]{6}{*}{$t 6^{\mathrm{h}} \mathrm{a}$} & $s^{h} \mathrm{a}$ & 4.08 & 2.50 & 4.88 & - & - & 5.41 \\
\hline & $\mathrm{k}^{\mathrm{h}} \mathrm{a}$ & 12.24 & 27.50 & 2.44 & - & 5.00 & 13.51 \\
\hline & $\mathrm{t}^{\mathrm{h}} \mathrm{a}$ & 22.45 & 20.00 & 14.63 & 18.42 & 32.50 & 10.81 \\
\hline & $\mathrm{p}^{\mathrm{h}} \mathrm{a}$ & 59.18 & 50.00 & 75.61 & 81.58 & 60.00 & 70.27 \\
\hline & tढิa & 2.04 & - & 2.44 & - & - & - \\
\hline & ha & - & - & - & - & 2.50 & - \\
\hline \multirow[t]{6}{*}{$\mathrm{k}^{\mathrm{h}} \mathrm{a}$} & $s^{\mathrm{h}} \mathrm{a}$ & 1.85 & - & - & 1.43 & 3.08 & 6.25 \\
\hline & $t 6^{\mathrm{h}} \mathrm{a}$ & 35.19 & 37.04 & 30.00 & 31.43 & 38.46 & 23.44 \\
\hline & $\mathrm{t}^{\mathrm{h}} \mathrm{a}$ & 20.37 & 24.07 & 18.34 & 21.43 & 29.23 & 28.13 \\
\hline & $\mathrm{p}^{\mathrm{h}} \mathrm{a}$ & 42.59 & 37.04 & 51.67 & 44.29 & 26.15 & 40.63 \\
\hline & $\widehat{t} \mathrm{ta}$ & - & 1.85 & - & 1.43 & 1.54 & - \\
\hline & ha & - & - & - & - & 1.54 & 1.56 \\
\hline \multirow[t]{6}{*}{$\mathrm{t}^{\mathrm{h}} \mathrm{a}$} & $\mathrm{s}^{\mathrm{h}} \mathrm{a}$ & - & - & - & 1.43 & 3.28 & 4.76 \\
\hline & $\mathrm{tc}^{\mathrm{h}} \mathrm{a}$ & 29.69 & 34.29 & 31.15 & 25.71 & 31.15 & 33.34 \\
\hline & $\mathrm{k}^{\mathrm{h}} \mathrm{a}$ & 31.25 & 35.71 & 19.67 & 17.14 & 22.95 & 25.40 \\
\hline & $\mathrm{p}^{\mathrm{h}} \mathrm{a}$ & 39.06 & 30.00 & 49.18 & 54.29 & 42.62 & 34.92 \\
\hline & ha & - & - & - & - & - & 1.59 \\
\hline & pa & - & - & - & 1.43 & - & - \\
\hline \multirow[t]{6}{*}{$\mathrm{p}^{\mathrm{h}} \mathrm{a}$} & $s^{h} \mathrm{a}$ & 1.72 & 1.64 & - & - & 6.25 & 9.26 \\
\hline & $\mathrm{tc}^{\mathrm{h}} \mathrm{a}$ & 37.93 & 24.59 & 48.94 & 43.48 & 43.75 & 31.48 \\
\hline & $\mathrm{k}^{\mathrm{h}} \mathrm{a}$ & 34.48 & 32.79 & 21.28 & 13.04 & 12.50 & 27.78 \\
\hline & $\mathrm{t}^{\mathrm{h}} \mathrm{a}$ & 25.86 & 39.34 & 27.66 & 41.30 & 35.42 & 31.48 \\
\hline & $\widehat{t c a}$ & - & - & 2.13 & 2.17 & - & - \\
\hline & ha & - & 1.64 & - & - & 2.08 & - \\
\hline
\end{tabular}

FRT (approximately $70 \mathrm{~ms}$ ), MRT (approximately $200 \mathrm{~ms}$ ), and SRT (approximately $600 \mathrm{~ms}$ ). FRT: fast release time, MRT: medium release time, SRT: slow release time 
$600 \mathrm{~ms}$ 전후의 SRT에 비해 높게 나타나 한국어음의 인지도는 RT에 영향을 받을 수 있음을 확인하였다.

본 연구에서 RT에 따른 무의미음절인지도는 청취 환경에 따 른 차이는 나타나지 않았다. Kong et al.(2013)의 연구에서 조 용한 곳에서의 무성자음인지도는 $0 \mathrm{~dB}$ 이상의 SNR에서는 차 이가 나타나지 않아서 본 연구와 일치성을 나타냈다.

무의미음절인지도는 조용한 환경에서는 RT에 따른 차이가 나타나지 않았으나, $6 \mathrm{~dB} \mathrm{SNR}$ 의 잡음 환경에서는 FRT가 $\mathrm{MRT}$ 및 SRT에 비해 높게 나타났으나, FRT와 SRT 간에는 차 이가 나타나지 않았다. Han et al.(2017)의 연구에서는 한국형 보청기적합공식을 개발하기 위하여 한국에서 개발한 8 채널의 보청기를 이용하여 RT에 따른 어음의 청취능력을 알아보았다. 대상자는 61 세에서 80 세의 감각신경성 난청인이었으며, RT는 $50 \mathrm{~ms}$ 와 $500 \mathrm{~ms}$ 로 조절하여 어음청취역치(speech recognition threshold) 및 이에 필요한 SNR로 어음청취능력을 알아보았는 데 RT 간에 유의미한 차이는 나타나지 않았다. RT가 $100 \mathrm{~ms}$ 이하로 빠를 때 작은 에너지의 신호음과 잡음을 증폭하고, RT 가 수백 $\mathrm{ms}$ 이상으로 느릴 때 신호음과 잡음을 억제하여 SNR 을 개선하는 효과를 감안할 때 $70 \mathrm{~ms}$ 와 $600 \mathrm{~ms}$ 에서 무의미음 절인지도의 차이가 나타나지 않은 본 연구와 일치성을 나타냈 다. 그러나 Han et al.(2017)의 연구에서는 $200 \mathrm{~ms}$ 전후의 RT 에 따른 어음청취역치 및 어음인지에 필요한 SNR을 확인하지 않아서 본 연구와의 차이를 확인할 수는 없었다. Pottackal Mathai \& Mohammed(2017)의 연구에서 양이보청기를 착용 한 후 문장을 $40 \mathrm{~dB} \mathrm{HL}, 60 \mathrm{~dB} \mathrm{HL}$ 및 $80 \mathrm{~dB}$ HL의 강도로 제시하였을 때, 감각신경성 난청인은 $10 \mathrm{~ms}$ 보다 $2,000 \mathrm{~ms}$ 일 때 SNR-50이 높게 나타나 느린 RT일 때 SNR이 개선되어 본 연 구와 일치성을 나타냈다. 그리고 본 연구에서의 RT에 따른 무 음절인지도는 $200 \mathrm{~ms}$ 일 때 $70 \mathrm{~ms}$ 와 $600 \mathrm{~ms}$ 에 비해서 높게 나 타났다. 본 연구의 실험에 사용한 보청기는 17 채널의 보청기로 압축 시스템은 17 개 각각의 채널에서 독립적으로 작동한다. 비 선형 보청기에서 RT가 빠르면 작은 에너지의 어음을 증폭하여 CVR을 개선할 수 있으며, 느린 RT의 경우는 주변의 잡음을 억 제하여 SNR을 개선할 수 있지만 동시에 두 가지 모두를 개선 할 수는 없다(Souza, 2002). 그러나 다채널 보청기에서 RT를 $200 \mathrm{~ms}$ 로 설정한 경우 $70 \mathrm{~ms}$ 에 비해서 잡음은 어느 정도 줄어 들고 $\mathrm{CVR}$ 을 개선하기 어렵지만 고주파수 채널의 이득을 환원 하는 효과가 있다. 그리고 $200 \mathrm{~ms}$ 의 RT는 $600 \mathrm{~ms}$ 에 비해서 $\mathrm{SNR}$ 은 나쁘게 나타나지만 저주파수 채널의 이득을 줄여서 $\mathrm{SNR}$ 을 개선하는 효과가 있다. 이를 종합해 보면 $200 \mathrm{~ms}$ 의 RT 에서 잡음하의 무의미음절의 인지도가 높게 나타난 본 연구의 결과는 합당한 것으로 생각한다.

Souza \& Kitch(2001)는 경도에서 심도의 감각신경성 난청인
은 다채널의 경우 어음인지도를 개선할 수 있다고 하였으며, Alexander \& Masterson(2015)의 연구에서는 RT와 채널에 따 른 효과를 보기 위하여 4 채널, 8 채널 그리고 16 채널의 모의 실험에서 큰 차이는 아니었으나 RT와 관계없이 빠른 RT에서 는 4 채널, 느린 RT에서 16 채널의 인지도가 높다고 하였다. 또 한 Henning \& Bentler(2008)의 연구에 따르면 빠른 RT와 채 널에 따른 효과를 확인하였을 때, 유의미한 차이가 나타나지 않았다. 하지만 RT의 주 효과가 압축 효율을 결정하는 가장 중 요한 요인으로 나타나 가장 효과적인 압축은 실제로 가장 빠른 RT와 고 채널에서 출현하는 경향이 있다고 한다. 그러나 본 연 구에서는 17 채널의 보청기만을 사용하여 채널에 대한 효과는 확인할 수 없었다.

선호도에 있어서는 조용한 환경 및 잡음 환경에서 선명도, 잡음의 크기 및 전체 선호도는 RT에 따른 차이가 나타나지 않 았다. Gilbert et al.(2008)의 연구에서는 51 76세의 난청인 25 명을 대상으로 RT가 5, 50, 500, 5,000 ms로 조작된 문장을 들 려주고 비교하였다. 상기의 연구에서 난청인들은 RT에 따른 성 능의 차이를 구분하지 못했다고 보고하였는데 본 연구에서도 5 명을 제외한 15 명의 대상자가 65 세 이상의 노인으로 일치성을 나타냈다.

Neuman et al.(1998)의 연구에서는 20명의 감각신경성 난청 인을 대상으로 RT를 $60,200,1,000 \mathrm{~ms}$ 로 조절하여 10점 척도 를 통해 음질을 평가하였을 때, 부드러움, 배경 소음 및 음량의 강도에서 유의한 차이가 나타나 본 연구와 차이가 나타났지만, 선명도 및 전체적 선호도는 RT에 따라 변화가 나타나지 않아 본 연구와 일치성을 보였다. 그리고 Kong et al.(2013)과 Lee \& Lee(2010)의 연구에서는 조용한 곳 또는 무성자음의 CVR이 6 $\mathrm{dB}$ 이상일 때 인지도의 차이가 나타났다고 하였다. 그러나 무성 자음에서 CVR이 $6 \mathrm{~dB}$ 이상이 되려면 빠른 압축(fast acting compression)에서 $\mathrm{CR}$ 이 2:1 이상 충분해야 하는데 본 연구에 서의 $\mathrm{CR}$ 은 다소 부족했던 것으로 보인다.

본 연구에서는 RT의 효과가 나타날 수 있도록 선행 자음이 고주파수 대역의 스펙트럼을 갖는 무성자음 2 개를 연결하여 사용하였다. 그러나 일상의 대화음 내에는 다양한 모음, 유성 및 무성자음을 다양하게 포함하고 있어서 본 연구의 결과가 RT에 따른 어음인지도를 대표한다고 할 수는 없다.

Oh et al.(2000)에 따르면 난청인의 오류 패턴은 말소리 산출 위치와 연관성이 높으며, 시각적 단서가 적은 음소에서 오류가 더욱 많이 나타났다. 본 연구의 음소별 대치는 대부분의 음소 가 전방화가 나타나 일치성을 보였다.

또한 본 연구에서 한국어 음운 체계에 따라 조음방법 및 조 음 위치에 따른 측면에서 오류 유형으로 분류하였을 때, 조용 한 환경 및 잡음 환경에서 모두 조음방법에 따른 대치가 마찰 
음, 파열음, 파찰음 순서로 오류율이 낮아졌으며, 위치에 따라 서 또한 치조음, 연구개음, 양순음, 경구개음 순으로 나타나 동 일한 양상을 보여 환경에 따라서 오류 패턴에 따른 차이는 나 타나지 않았다고 볼 수 있다.

본 연구의 한계점으로는 대상자들의 청력역치레벨의 정도와 역동범위, 단어인지도, 보청기 착용 및 순응(acclimatization) 기간을 고려하지 않았으며, 제시어음은 무의미음절, 잡음은 백 색잡음으로 제한적이었다. 또한 본 연구에서 사용한 보청기가 다채널임에도 RT를 주파수 대역별로 조절하지 않았다. 따라서 향후에는 대상자들의 청력역치레벨, 단어인지도, 순응 기간, 나 이 등 대상자의 조건, 다양한 종류와 강도의 제시어음과 잡음, 다채널 보청기의 주파수 대역별 RT 등을 고려하여 한국어음의 인지에 RT를 확인하여야 할 것이다.

본 연구의 결과를 통하여 한국어 무성자음의 인지는 RT에 영향을 받을 수 있음을 확인하였다. 따라서 향후 한국어음의 인지에 효과적인 보청기적합공식의 개발을 위해서는 어음의 인 지와 신호대잡음비, 선명도 또는 선호도를 고려하여 RT를 산 출하는 것이 한국 난청인의 의사소통능력의 개선에 도움을 줄 수 있을 것으로 생각한다.

중심 단어 : 보청기·해제시간·압축역치·압축비율·보청기적합 공식.

\section{Ethical Statement}

This study was approved by the Institutional Review Board of Hallym University of Graduate Studies (IRB \# HUGSAUD 142830).

\section{Acknowledgments}

The authors thank to GN Hearing Korea and our participants.

\section{Declaration of Conflicting Interests}

There are no conflict interests.

\section{Funding}

This research was completed while being supported by National Research Foundation of Korea (2018R1A2B6001986).

\section{REFERENCES}

Alexander, J. M. \& Masterson, K. (2015). Effects of WDRC release time and number of channels on output SNR and speech recognition. Ear and Hearing, 36(2), e35-e49.

American National Standards Institute. (1992). ANSI S3.42-1992: Testing Hearing Aids with a Broad-Band Noise Signal. New York, NY: Acoustical Society of America.

American National Standards Institute. (2003). ANSI S3.22-2003: Specification of Hearing Aid Characteristics. New York, NY: Acoustical Society of America.

Barker, C. \& Dillon, H. (1999). Client preferences for compression threshold in single-channel wide dynamic range compression hearing aids. Ear and Hearing, 20(2), 127-139.

Barker, C., Dillon, H., \& Newall, P. (2001). Fitting low ratio compression to people with severe and profound hearing losses. Ear and Hearing, 22(2), 130-141.
Boike, K. T. \& Souza, P. E. (2000). Effect of compression ratio on speech recognition and speech-quality ratings with wide dynamic range compression amplification. Journal of Speech, Language, and Hearing Research, 43(2), 456-468.

Byrne, D., Dillon, H., Ching, T., Katsch, R., \& Keidser, G. (2001). NAL-NL1 procedure for fitting nonlinear hearing aids: Characteristics and comparisons with other procedures. Journal of the American Academy of Audiology, 12(1), 37-51.

Choi, M, J. \& Lee, K, W. (2011). Case reports of improving sound quality by compression threshold control. Audiology and Speech Research, 7(1), 100-105.

Gatehouse, S., Naylor, G., \& Elberling, C. (2006). Linear and nonlinear hearing aid fittings-1. Patterns of benefit. International Journal of Audiology, 45(3), 130-152.

Gilbert, G., Akeroyd, M. A., \& Gatehouse, S. (2008). Discrimination of release time constants in hearing-aid compressors. International Journal of Audiology, 47(4), 189-198.

Han, W., Lee, J., Kim. J., Lee, K., \& Kim, D. (2017). Preferred compression threshold and release time in quiet and noisy conditions for elderly Korean hearing aid users. Journal of Audiology and Otology, 21(3), 133-139.

Hansen, M. (2002). Effects of multi-channel compression time constants on subjectively perceived sound quality and speech intelligibility. Ear and Hearing, 23(4), 369-380.

Henning, R. L. \& Bentler, R. A. (2008). The effects of hearing aid compression parameters on the short-term dynamic range of continuous speech. Journal of Speech, Language, and Hearing Research, 51(2), 471-484.

Jenstad, L. M. \& Souza, P. E. (2005). Quantifying the effect of compression hearing aid release time on speech acoustics and intelligibility. Journal of Speech, Language, and Hearing Research, 48(3), 651-667.

Jin, I. K., Kates, J. M., Lee, K., \& Arehart, K. H. (2015). Derivations of the band-importance function: A cross-procedure comparison. The Journal of the Acoustical Society of America, 138(2), 938-941.

Kong, H. K., Joo, Y. M., \& Lee, K. W. (2013). Nonsense syllable recognition scores as a function of consonant-to-vowel ratios in speech noise for sensorineural hearing loss. Audiology and Speech Research, 9(1), 33-39.

Lee, K. W. \& Kim, J. S. (2011). Suggestion of hearing aid gain for Korean Hearing Impaired (HAG-K). Audiology and Speech Research, 7(2), 119123.

Lee, K. W. \& Kim, J. S. (2012). The study of frequency importance function of the Korean monosyllabic words. Audiology and Speech Research, $8(1), 24-33$.

Lee, K. W., Lee, J. H., \& Lee, J. H. (2008a). Comparing 2-cc coupler gain of monaural fitting with non-linear fitting formulas for elderly Korean with SNHL. Audiology and Speech Research, 4(1), 69-73.

Lee, K. W., Lee, J. H., \& Lee, J. H. (2008b). Suggestions of multi-talker babble noise using Korean speech sound. Audiology and Speech Research, 4(1), 24-27.

Lee, S. Y. (2008). Case report for background noise reduction by compression threshold (CT) control in non-programmable hearing aids. $A u$ diology and Speech Research, 4(2), 199-203.

Lee, S. Y. \& Lee, K. W. (2010). Effects of word recognition score as a function of consonant-to-vowel ratio (CVR) in Korean non-sense syllables. Audiology and Speech Research, 6(1), 25-29.

Neuman, A. C., Bakke, M. H., Mackersie, C., Hellman, S., \& Levitt, H. (1995). Effect of release time in compression hearing aids: Paired-comparison judgments of quality. The Journal of the Acoustical Society of America, 98(6), 3182-3187.

Neuman, A. C., Bakke, M. H., Mackersie, C., Hellman, S., \& Levitt, H. (1998). The effect of compression ratio and release time on the categorical rating of sound quality. The Journal of the Acoustical Society of America, 103(5 Pt 1), 2273-2281.

No, B. I. \& Lee, J. H. (2012). A comparison study of monosyllable recognition in listeners with sloping versus flat hearing loss types. Audiology and Speech Research, 8(1), 78-86.

Oh, Y. J., Zhi, M. Z., \& Kim, Y. T. (2000). Acoustic comparisons of vowel 
and plosive productions between the normal and the hearing-impaired children. Speech Sciences, 7(2), 51-70.

Pottackal Mathai, J. \& Mohammed, H. (2017). Effect of hearing aid release time and presentation level on speech perception in noise in elderly individuals with hearing loss. European Archives of Oto-Rhino-Laryngology, 274(2), 671-677.
Souza, P. E. (2002). Effects of compression on speech acoustics, intelligibility, and sound quality. Trends in Amplification, 6(4), 131-165.

Souza, P. E. \& Kitch, V. (2001). The contribution of amplitude envelope cues to sentence identification in young and aged listeners. Ear and Hearing, 22(2), 112-119. 